OPEN ACCESS

Edited by:

Rui Diogo,

Howard University, USA

Reviewed by:

Ariel D. Chipman,

Hebrew University of Jerusalem, Israel

Natalia Siomava,

Howard University, USA

*Correspondence:

Nigel C. Hughes

nigel.hughes@ucr.edu

Specialty section:

This article was submitted to Evolutionary Developmental Biology,

a section of the journal

Frontiers in Ecology and Evolution

Received: 10 February 2017 Accepted: 07 April 2017 Published: 04 May 2017

Citation: Hughes NC, Hong PS, Hou JB and Fusco G (2017) The Development of the Silurian Trilobite Aulacopleura koninckii Reconstructed by Applying Inferred Growth and Segmentation Dynamics: A Case Study in

Paleo-Evo-Devo.

Front. Ecol. Evol. 5:37.

doi: 10.3389/fevo.2017.00037

\section{The Development of the Silurian Trilobite Aulacopleura koninckii Reconstructed by Applying Inferred Growth and Segmentation Dynamics: A Case Study in Paleo-Evo-Devo}

\author{
Nigel C. Hughes ${ }^{1 *}$, Paul S. Hong ${ }^{2}$, Jinbo Hou ${ }^{1}$ and Giuseppe Fusco ${ }^{3}$ \\ ${ }^{1}$ Department of Earth Sciences, University of California, Riverside, CA, USA, ${ }^{2}$ Korea Institute of Geoscience and Mineral \\ Resources, Daejeon, South Korea, ${ }^{3}$ Department of Biology, University of Padova, Padova, Italy
}

Fossilized growth series provide rare glimpses into the development of ancient organisms, illustrating descriptively how size and shape changed through ontogeny. Occasionally fossil preservation is such that it is feasible to test alternative possibilities about how ancient development was regulated. Here we apply inferred developmental parameters pertaining to size, shape, and segmentation in the abundant and well-preserved 429 Myr old trilobite Aulacopleura koninckii that we have investigated previously to reconstruct the post-embryonic ontogeny of this ancient arthropod. Our published morphometric analyses associated with model testing have shown that: specification of the adult number of trunk segments (polymorphic in this species) was determined precociously in ontogeny; that growth regulation was targeted (i.e., compensatory), such that each developmental stage exhibited comparable variance in size and shape; and that growth gradients operating along the main body axis, both during juvenile and adult ontogeny, resulted from a form of growth control based on positional specification. While such developmental features are common among extant organisms, our results represent the oldest evidence for them within Metazoa. Herein, the novel reconstruction of the development of Aulacopleura koninckii permits visualization of patterns of relative and absolute growth and segmentation as never before possible for a fossilized arthropod ontogeny. By conducting morphometric analysis of appropriate data sets it is thus possible to move beyond descriptive ontogenetic studies and to address questions of high interest for evolutionary developmental biology using data from fossils, which can help elucidate both how developmental processes themselves evolve and how they affect the evolution of organismal body patterning. By extending similar analyses to other cases of exceptional preservation of fossilized ontogeny, we can anticipate beginning to realize the research program of "paleo-evo-devo."

Keywords: allometry, Arthropoda, evolutionary developmental biology, growth, ontogeny, segmentation 


\section{INTRODUCTION}

The central idea of evolutionary developmental biology (evodevo) is that including information about developmental processes provides for a more complete explanation of observed evolutionary patterns, because evolutionary change is shaped not only by different processes of sorting of standing variation, such as natural selection, but also by the variation that arises at each generation, which depends on developmental systems (Fusco, 2001, 2015).

The comparative approach is one of the main instruments of analysis in evo-devo studies (Müller, 2007), serving in both reconstructing the evolution of developmental systems and in exploring how developmental processes can themselves affect organismal evolution (Moczek, 2015). Gaining access to the state of developmental characters in extinct organisms, through the study of so-called "fossilized ontogenies," increases the power of the comparative analysis, by introducing novel, diachronic observational data (Fusco et al., 2016).

The study of fossil organisms with a focus on their development, aimed at the study of the evolution of more inclusive groups to which they belong, has been dubbed "palaeoevo-devo" (Minelli and Fusco, 2008, p. 216), and since applied in several articles, books, symposia and websites (e.g., Haug et al., 2013; Wilson, 2013; Kliman, 2016; http://palaeo-evo-devo. info/). Paleo-evo-devo studies rest, however, on the availability of detailed records of development in fossil species, which is not at all common (Sánchez, 2012). Among the few exceptions there is a major arthropod clade, the Trilobita, which has a record of fossilized ontogenies that is among the most comprehensive for any extinct group (Hughes, 2003).

Herein, based on the results of an extended series of morphometric analysis we conducted during the last 25 years, we review the development of the middle Silurian trilobite A. koninckii (Barrande, 1846) (Figure 1) and present the first reconstruction of its post-embryonic ontogeny. The extraordinary abundance of well-preserved complete exoskeletons of this species provides an unparalleled opportunity to explore post-embryonic development in an early arthropod, so that it has recently become one of the most intensely studied trilobite species.

Current understanding of the development of this 429 million year old arthropod goes beyond descriptive patterns of growth and segmentation. Considerable information has been discovered about how specific developmental pathways were taken and how different mechanisms of developmental control operated in this animal. In this respect, the A. koninckii developmental system reveals several features that are found in modern organisms, and whose occurrence in this animal represents their most ancient evidence.

Taking advantage of these findings, the novel reconstruction of A. koninckii ontogeny presented here is not simply a series of drawings representing the main features of sequential developmental. Rather, the drawings are based on morphometric character estimates that were derived by applying the growth and segmentation dynamics revealed in our prior published work (see Supplementary Appendix). This distinguishes this

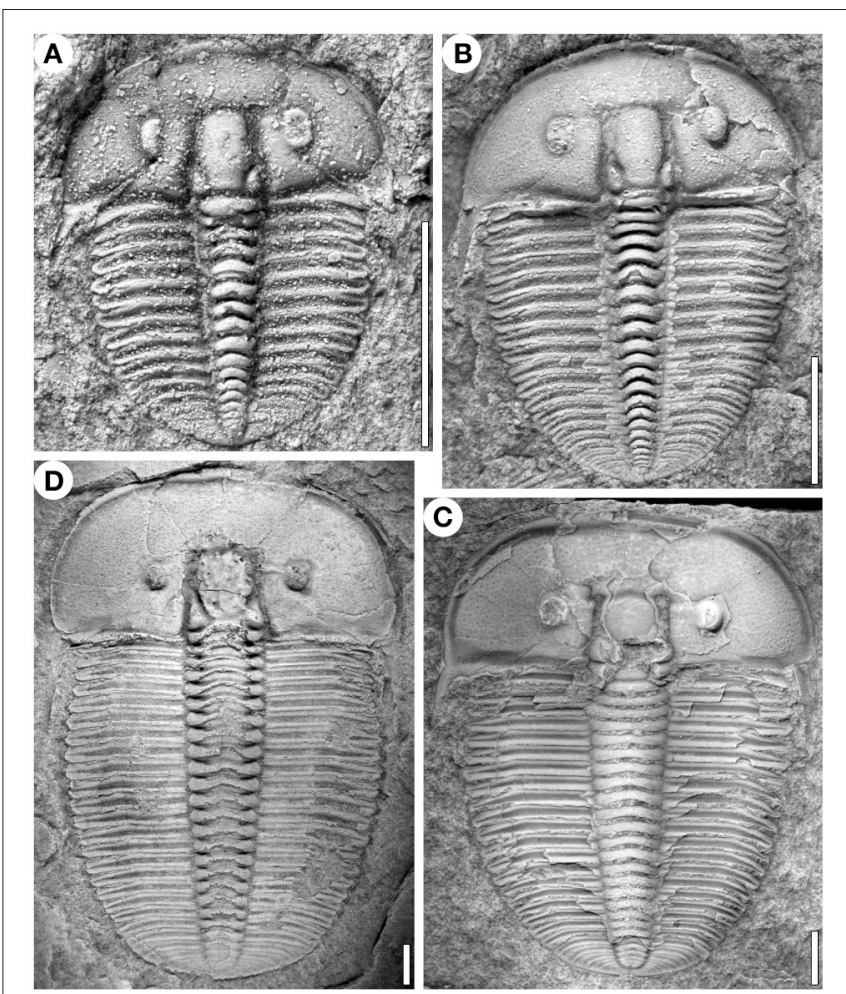

FIGURE 1 | Specimens of Aulacopleura koninckii at different developmental stages (see text). (A) $\mathrm{s}_{12} \cdot$ (B) $\mathrm{s}_{17} \cdot$ (C) ca. $\mathrm{s}_{27} \cdot$ (D) ca. $\mathrm{s}_{30}$. (A,B and D) from Na Černidlech, Czech Republic, and (C) from Arethusina Gorge, Czech Republic. Scale bars $2 \mathrm{~mm}$.

reconstruction of a trilobite ontogeny from any other that we know of published to date. In order to explain and justify these estimates, this paper illustrates sequentially different aspects of A. koninckii development, in which the previous findings provide the basis for the present ontogeny reconstruction. Combining different developmental dynamics together permits us to visualize patterns of relative and absolute growth and segmentation as never before possible for a fossilized arthropod ontogeny.

Although, the development of A. koninckii cannot be claimed to represent the whole clade Trilobita (more than 20,000 species in the whole group, spread across a 250 Myr time interval), its study shows that it is possible to use data from fossils to address questions of high interest for evolutionary developmental biology, demonstrating that paleo-evo-devo is a well-defined research program (sensu Müller, 2007) in the study of evolutionary change.

\section{OUTLINE OF TRILOBITE DEVELOPMENT}

In order to contextualize the investigations of A. koninckii development, firstly we outline some general features of trilobite post-embryonic development.

The onset of exoskeletal biomineralization in trilobites presumably initiated shortly after hatching, allowing fossil 
preservation since the earliest post-embryonic stages. Development was direct, lacking drastic metamorphosis, and the gradually changing forms of the progressive developmental stages were separated by episodes of molting, as in extant arthropods. Quantitative data on successive molt stages are available for about 80 species of trilobites, including A. koninckii (Fusco et al., 2012).

Standard descriptions of trilobite ontogeny are based on the development of articulating joints between dorsal segments (Figure 2; see Hughes et al., 2006). An anterior set of conjoined segments comprised the head region or cephalon that seemingly had a fixed number of segments throughout ontogeny. The trunk region lay posterior to the cephalon and changed during ontogeny both in the number of segments expressed and in the number of articulating joints between segments.

The earliest widely recognized phase of trilobite ontogeny is the protaspid period, during which all body segments (both cephalic and trunk) formed an undivided dorsal shield (Chatterton and Speyer, 1997). This period typically embraced a small number of stages. Later stages were characterized by the appearance of a series of articulations between dorsal segments, the first of which occurred at the cephalic-trunk boundary.

The appearance of the cephalic-trunk articulation marked entry into the meraspid period, which divided the dorsal exoskeleton into two components, the cephalon and a set of conjoined trunk segments called the pygidium. During subsequent meraspid molts, new articulations developed sequentially at the posterior of the leading pygidial segment (in most species, one per molt), resulting in a set of articulating trunk segments, collectively called the thorax, that were located in front of the pygidium. In parallel, new trunk segments appeared sequentially in a subterminal zone within the pygidium. The rate at which segments were released into the thorax relative to the rate at which segments were expressed in the subterminal growth zone determined the number of segments allocated to the meraspid pygidium, and varied among species (see Hughes et al., 2006). The meraspid pygidium thus comprised a dynamically changing complement of segments (Minelli et al., 2003). Progressive release of trunk segments into the thorax continued until the animal entered the final, holaspid period of development which was characterized by a stable number of thoracic segments.

Like many extant arthropods (including several myriapod lineages, Minelli and Fusco, 2013), trilobites displayed hemianamorphic development (Minelli et al., 2003), i.e., they added new trunk segments during post-embryonic life until a fixed adult number was reached at a given stage, after which growth and molting continued but without any further increase in segment number. Trilobite ontogeny can thus be subdivided into an anamorphic phase, during which new trunk segments appeared at the rear of the trunk, and a subsequent epimorphic phase, during which the number of trunk segments remained constant (Figure 2). There was variation among (and in some cases, possibly within) species in whether onset of epimorphosis preceded (protomeric development), occurred synchronously with (synarthromeric development), or succeeded (protarthrous development) onset of the holaspid phase (Hughes et al., 2006).

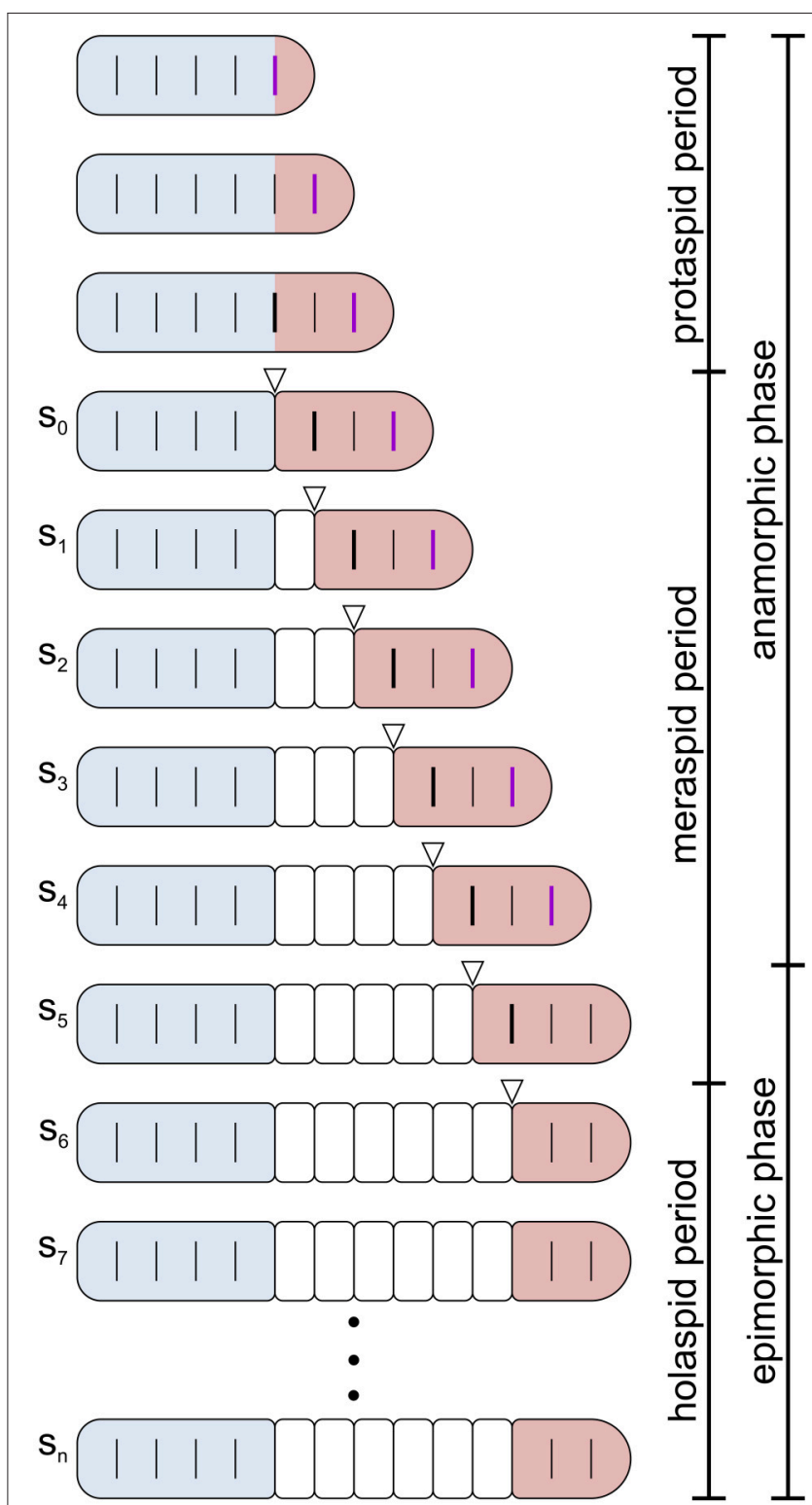

FIGURE 2 | Schematic representation of post-embryonic segmentation in a trilobite. Dorsal view. Increase in size is not represented and segmentation schedule and patterns do not correspond to any specific species ontogeny. Colors highlight the three main body regions in trilobites: cephalon, blue; thorax, white; pygidium, red. Transverse lines reaching the margins indicate articulated segmental boundaries, whereas incomplete transverse lines indicate segmental boundaries that are not functional articulations. A thick black incomplete segmental boundary in the pygidium indicates the place where a new articulation will emerge at the next molt, and a thick purple incomplete segmental boundary indicates the place where a new trunk segment will emerge at the next molt. Open arrowheads indicate the new articulation just developed. The bars on the right indicate the division of trilobite post-embryonic life into three periods (protaspid, meraspid, and holaspid periods, see text) and into two phases (anamorphic and epimorphic phases of the hemianamorphic development, see text). In the specific case depicted, the onset of the epimorphic phase (termination of trunk segment addition) preceded the onset of the holaspid period (termination of thoracic segment release). However, this was not the case for all trilobite taxa, and not for Aulacopleura koninckii, where the onset of the epimorphic phase coincided with the onset of the holaspid period. Post-protaspid stages are labeled $s_{0}-s_{n}$. 


\section{AULACOPLEURA KONINCKII FOSSIL RECORD}

Large numbers of articulated exoskeletons of A. koninckii covering a broad span of juvenile and adult ontogeny occur on multiple bedding plane surfaces within an $1.4 \mathrm{~m}$ interval of mudstone on $\mathrm{Na}$ Černidlech Hill near Loděnice in the Czech Republic. This interval likely accumulated over a period of a few thousand years (Hughes et al., 2014). Both physical evidence preserved in the sedimentary rocks hosting the fossils and in the form and occurrence of the biota itself (which includes many species other than A. koninckii) suggest an environment of fluctuating oxygen availability in which numbers of $A$. koninckii, which had a morphology commonly associated with oxygen-poor settings, periodically bloomed (Hughes et al., 2014). The locality was first excavated by the French-Czech paleontologist Joachim Barrande, likely in the 1840's, and almost all of the samples studied come from that excavation.

Aulacopleura koninckii belongs to the order Aulacopleurida, a long-lived and morphologically quite conservative group with origins within the wave of diversification of relatively derived trilobite clades early in the Ordovician (Hong et al., 2014). It has long been noted that A. koninckii is homeomorphic with trilobites from a variety of other clades, several of which were particularly common in low-oxygen settings in the Cambrian (Hughes et al., 1999), sharing a narrow axis (the central lobe running the length of the trilobite body), multiple homonomous trunk segments, and a small holaspid pygidium. This similarity is convergent, because more basal members of Aulacopleurida do not share this form.

Adult A. koninckii showed variation in the number of thoracic segments, from 18 to 22 , which partitioned the species into five distinct morphotypes. Intraspecific variation in adult thoracic segment number is a relatively rare condition among trilobites, especially among those younger to the Cambrian (Hughes et al., 1999).

Our investigations of $A$. koninckii during the last three decades have been based on three datasets, none of which was independent of the others. Early studies (e.g., Hughes and Chapman, 1995; Hughes et al., 1999) focused on a sample of 86 specimens available in museums in the USA and UK (dataset 1), but this dataset was expanded in later studies (e.g., Fusco et al., 2004) to 391 specimens that included those within Czech collections (dataset 2). Following a later comprehensive review of all materials available in the Czech National Museum and Czech Geological Survey, a third dataset (dataset 3) was compiled (Fusco et al., 2014, 2016; Hong et al., 2014) consisting of 352 specimens judged to include only the very best preserved specimens (more than 10,000 were inspected, Hong et al., 2014). This dataset, that included 163 of the same specimens included within the earlier, 391 specimen dataset 2 , is the one which provided the morphometric data used in the present study (Figure 3, Supplementary Data Sheet).

Protaspid stages are not known for A. koninckii, although comparison with congeneric species suggest up to three or more (Yuan et al., 2001). The three datasets include specimens that range from 4 to 22 thoracic segments. Specimens with
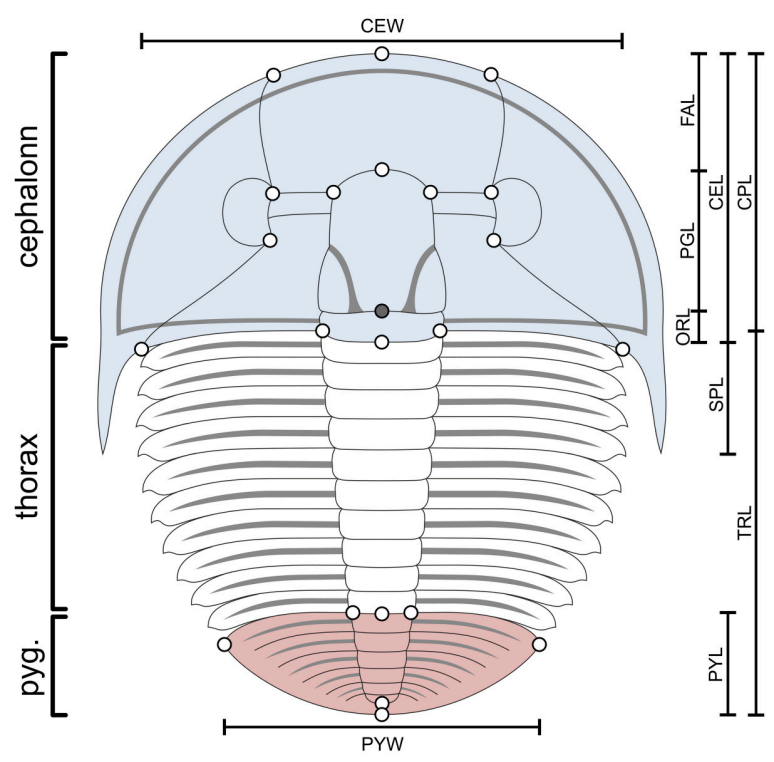

FIGURE 3 | Aulacopleura koninckii dorsal morphology. Colors highlight the three main body regions in trilobites: cephalon, blue; thorax, white; pygidium, red. Bars show the main morphometric characters used for ontogeny reconstruction herein (see Supplementary Appendix). CEL, cephalic axial length; CPL, cephalic paraxial length; CEW, cephalic width; FAL, frontal area length; PGL, preoccipital glabellar length; ORL, occipital ring length; SPL, genal spine length; TRL, trunk length; PYL, pygidial length; PYL, pygidial width. Empty circles are the position of the 22 landmarks used in the study of allometry (see Hong et al., 2014). The filled circle is the position of an additional landmark used for measuring the two most posterior sections of the cephalon (PGL and ORL). Landmarks used for measuring the length of each thoracic segment (TSL) are not shown (see text and Fusco et al., 2016). The number of thoracic segments varies among specimens (a stage $s_{10}$ meraspid specimen, with 10 thoracic segments, is illustrated here).

4-17 thoracic segments were certainly meraspid, but of unknown morphotype (assuming that the morphotype was already determined at that stage, see below), and specimens with 22 thoracic segments were certainly holaspids of the corresponding morphotype. However, small specimens with 18 to 21 thoracic segments represent a mix of late stage meraspids (of an undetermined morphotype with more segments) and early holaspids (of the morphotype with the same number of segments), while larger specimens with 18-21 thoracic segments were holaspids of the corresponding morphotype. Unfortunately, no associated characters have been found permitting assignment of any individual to a given morphotype when it is below a minimal size above which it can be confidently labeled holaspid (Hong et al., 2014). Post-protaspid stages are designated $s_{n}$, where $\mathrm{n}$ is a progressive natural number, starting from $s_{0}$ for the first meraspid stage.

\section{AULACOPLEURA KONINCKII SEGMENTATION}

\section{Polymorphism}

Aulacopleura koninckii is currently considered a single species that exhibits a polymorphism in the number of adult thoracic 
segments. This interpretation, first advanced by Barrande (1852), is supported by taphonomic and morphological evidence. Specimens co-occurring on single bedding plan surfaces, that were likely contemporaries, alive during the same season, could exhibit the full range of variation in the number of holaspid thoracic segment, and this pattern of synchronic variation was apparently present throughout the whole stratigraphic interval collected (possibly representing about 10,000 years, Hughes et al., 1999). In addition, no meristic characters other than thoracic segment number suggest more than a single species, while the degree of individual shape variation exhibited by adult $A$. koninckii is comparable to that of five other trilobite species recovered from the same site, which experienced the same broad environmental and preservational history (Hughes et al., 1999).

Intraspecific variation in the adult number of thoracic segments is a rare condition among trilobites (documented in some 20 or more species) and in the majority of these cases there are only two alternative numbers of thoracic segments, always consecutive. Interestingly, thoracic segment number polymorphism occurs more frequently among trilobite species, mostly of Cambrian age, that are homeomorphic with $A$. koninckii (Hughes et al., 1999).

Since in A. koninckii the modest variation in the number of pygidial segments is not associated to the variation in the number of thoracic segments (see Fusco et al., 2004 and below), adult segment number variation is in practice observable at the level of the whole trunk, as in extant arthropods.

Intraspecific, intrasexual adult variation in the number of trunk segments has evolved independently several times, and also occurs uncommonly among extant arthropods. Disregarding the clades that continue to molt and add segments throughout life, and for which it is not possible to distinguish static adult variation from ontogenetic variation (e.g., julid millipedes), intraspecific variation in clades with a developmentally targeted adult trunk segmental composition can be found only in a few arthropods lineages, occurring among geophilomorph and scolopendromorph centipedes, millipedes, and in notostracan crustaceans (Fusco and Minelli, 2013).

\section{Thoracic Segment Release}

Intraspecific variation in the number of adult thoracic segments in A. koninckii could result from different dynamics of thoracic segment release from the pygidium. In Fusco et al. (2004), we contrastively tested two alternative dynamics, consistent with some common mechanisms of developmental control in extant arthropods. The first was a minimal modification of the common developmental mode of the thorax in trilobites that allowed for some intraspecific variation in the stage (and therefore, for the number of thoracic segments) at which the release of thoracic segments ceased which marked the onset of the holaspid period. The second dynamic envisaged thoracic segment release potentially protracted throughout most of the animal ontogeny, associated with an irregular post-juvenile release schedule and a developmental threshold (e.g., a given body size; see Hughes and Chapman, 1995) at which the rate of thoracic segment release dropped significantly, regardless of the number of segments the animal possessed when reaching that threshold. The two dynamics produce different expectations among adult specimens: under the first dynamic, no association is expected between the number of thoracic segments and developmental stage, whereas under the second dynamic a small increase in the average number of thoracic segments with stage is expected.

We found no evidence of an association between the number of thoracic segments and the ontogenetic stage (Fusco et al., 2004), which strongly supports the view that A. koninckii had a standard, uninterrupted phase of thoracic segment release and that intraspecific variation in the number of adult thoracic segments derived from variation in the stage of the meraspid/holaspid transition (Figure 4).

\section{Trunk Segment Addition}

Among trilobites, the phase of thoracic segment release from the pygidium (meraspid period) and the phase of trunk segment addition (anamorphic phase) could be temporally offset. The former could be either shorter (protarthrous development), have the same length (synarthromeric development), or last longer (protomeric development) than the latter (Hughes et al., 2006). The three developmental modes produced increase, stasis, or a decrease in the number of pygidial segment during the holaspid period, respectively.

In A. koninckii pygidial segments are difficult to count. On the basis of dataset 3 , that with the most rigorous selection of specimens, most specimens of A. koninckii had 4-6 pygidial segments, while most specimens in dataset 2 were recorded as having 3-5. Irrespective of the difference in the two estimates, the number of pygidial segments is independent of stage (Fusco et al. (2004) on dataset 2; this study on dataset 3, non-significant linear regression coefficient) and morphotype (Fusco et al., 2004 on dataset 2; this study on dataset 3, non-significant group differences after Kruskal-Wallis test).

Accordingly, A. koninckii had synarthromeric development and the variation in the segmentation process among the five morphotypes was reflected in the duration of both the thoracic segment release and the trunk segment addition, which determined differences in the total number of trunk (thorax + pygidium) segments, and not simply in the duration of the phase of segmental release from the pygidium (Figure 4).

\section{Determination of the Morphotype}

The previous finding indicates that it was possible to recognize five morphotypes $\left(\mathrm{t}_{18}-\mathrm{t}_{22}\right)$ in $A$. koninckii, each corresponding to a different final number of thoracic segments, which ranged from 18 to 22 (Hughes and Chapman, 1995). This polymorphism could have had a genetic basis (genetic polymorphism) or have been the result of a form developmental plasticity in response to some unknown environmental cues (polyphenism). This issue cannot be resolved using our fossil data, but it was possible to test whether the determination of the morphotype was early or late in post-embryonic life.

In Fusco et al. (2004), we contrastively tested the two alternative hypotheses of a relatively early, or a late, determination of the morphotype in ontogeny. Under the first hypothesis morphotype determination preceded the stage of the meraspid/holaspid transition and was independent of the ontogenetic size progression. Under the second hypothesis, meraspid/holaspid transition was dependent on size, or on a 


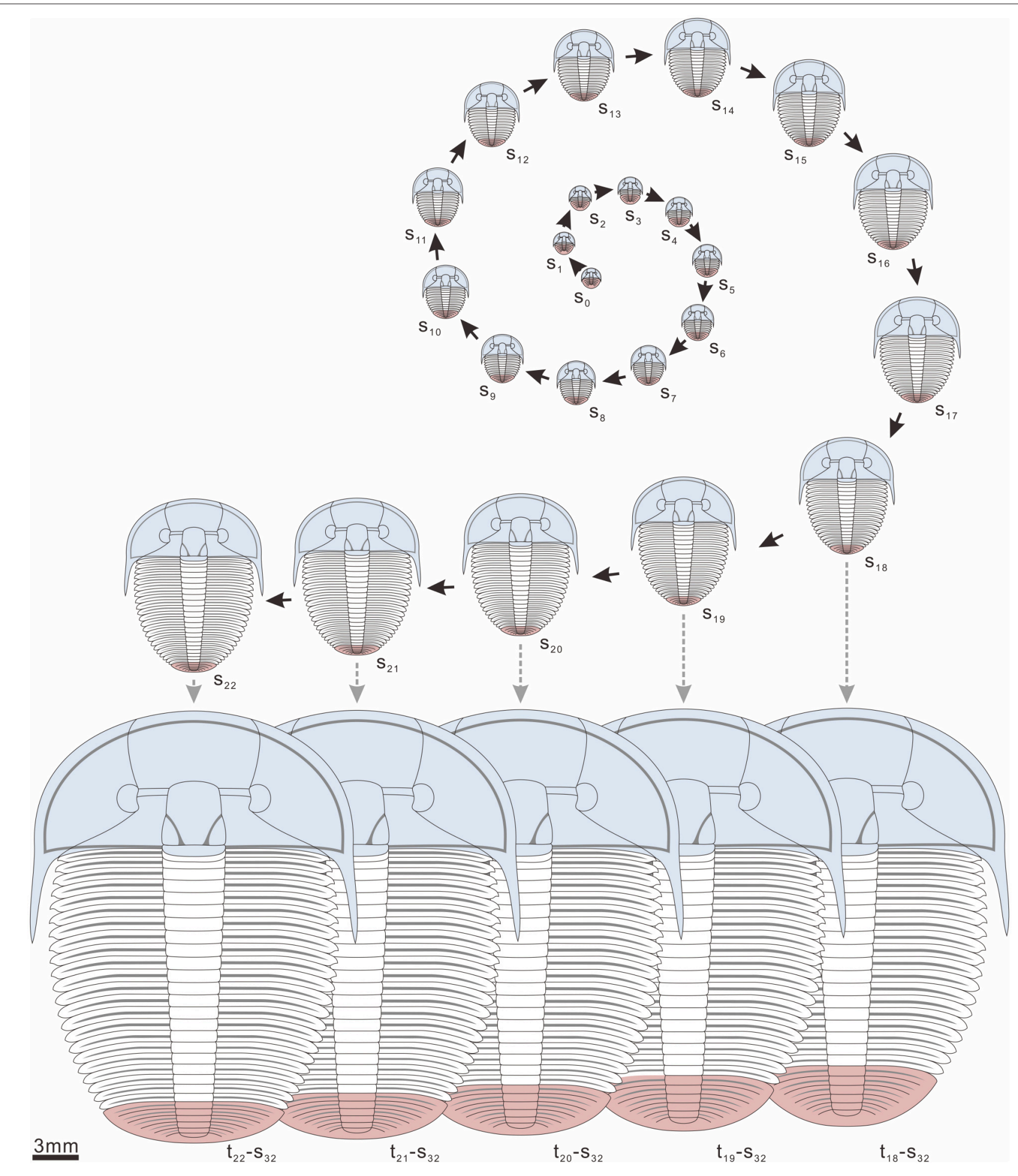

FIGURE 4 | Meraspid and holaspid ontogeny of the five morphotypes of $\boldsymbol{A}$. koninckii. Meraspid ontogeny of the five morphotypes extended through a different number of stages, from $s_{0}-s_{17}$ for morphotype $t_{18}$, to $s_{0}-s_{21}$ for morphotype $t_{22}$. All stages are shown at the same scale with respect to body length. (i) as specimens of the different morphotypes entered the holaspid period at a different stage (from $\mathrm{s}_{18}$ for $\mathrm{t}_{18}$, to $\mathrm{s}_{22}$ for $\mathrm{t}_{22}$ ) and trunk length growth rate was higher during meraspid period than in the holaspid period, at stage $s_{32}$ morphotypes with more thoracic segments tended to have longer trunks than the morphotypes with less thoracic segments, as a consequence of a prolonged meraspid period; (ii) as specimens of the different morphotypes terminated thoracic segment release at a different stage (from $s_{18}$ for $t_{18}$, to $s_{22}$ for $t_{22}$ ) and thoracic segment release had the effect of shortening the relative length of the pygidium (overwhelming the larger growth rate of the pygidium due to the growth gradient), at stage $s_{32}$ morphotypes with more thoracic segments tended to have relatively shorter pygidia than the morphotypes with less thoracic segments, as a consequence of more prolonged thoracic segment release. 


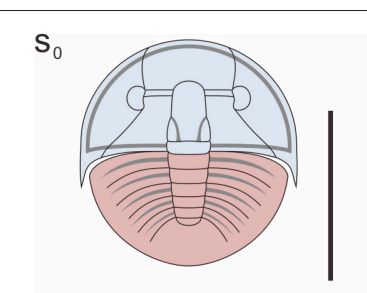

$\mathrm{S}_{5}$

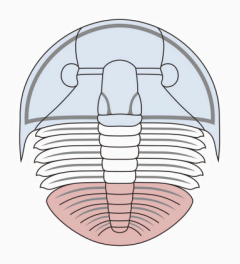

$\mathbf{S}_{10}$

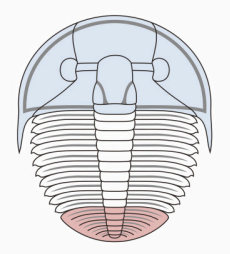

$\mathbf{S}_{15}$

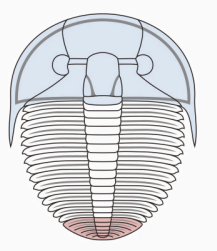

$\mathrm{S}_{20}$
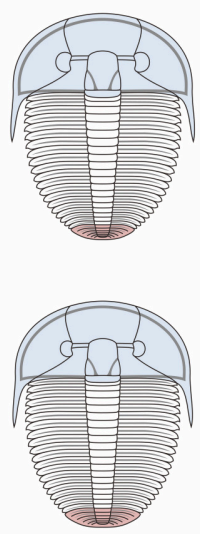

$\mathbf{S}_{30}$

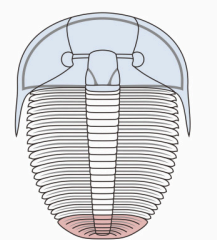

$\mathrm{s}_{1}$

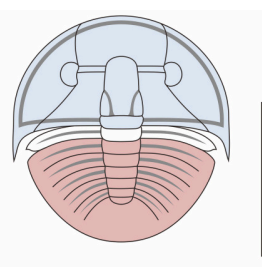

$\mathbf{S}_{6}$

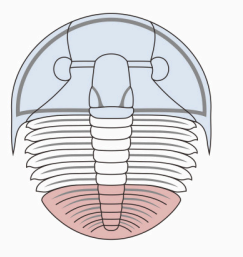

$\mathbf{S}_{11}$

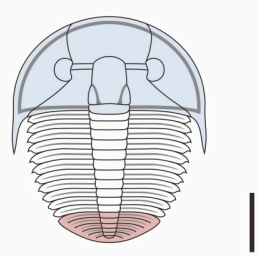

$\mathbf{S}_{16}$

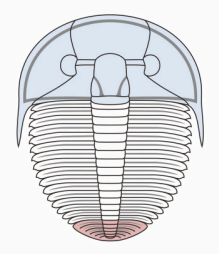

$\mathrm{S}_{21}$

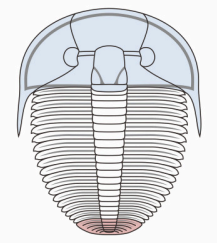

$\mathrm{S}_{26}$

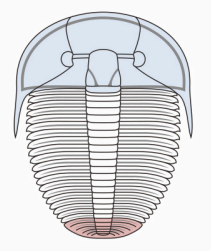

$\mathrm{S}_{31}$

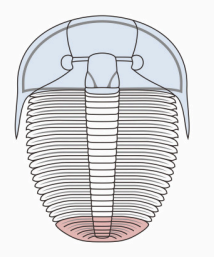

$\mathrm{S}_{2}$

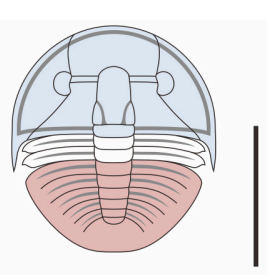

$\mathrm{S}_{7}$

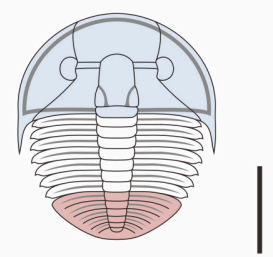

$\mathrm{S}_{12}$

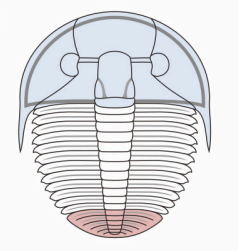

$\mathrm{S}_{17}$

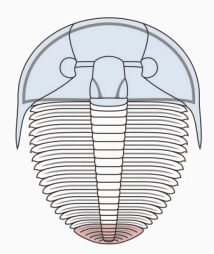

$\mathrm{S}_{22}$

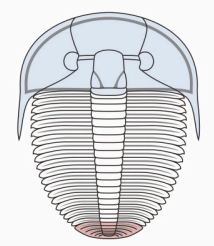

$S_{27}$

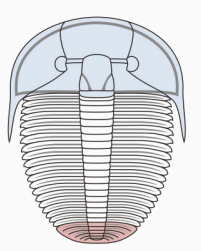

$\mathrm{S}_{32}$

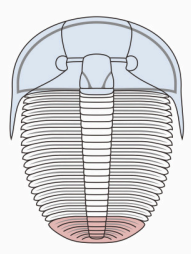

$\mathrm{S}_{3}$

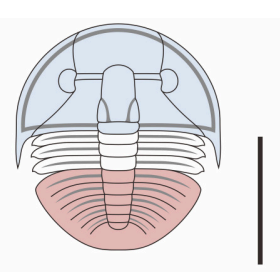

$\mathbf{S}_{8}$

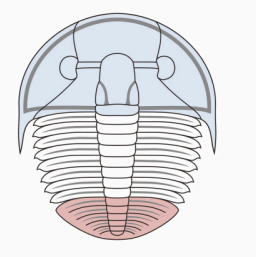

$\mathrm{S}_{13}$

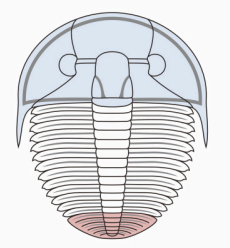

$\mathbf{S}_{18}$

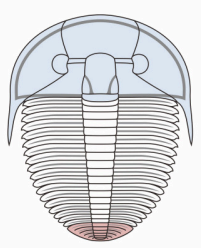

I

$\mathrm{S}_{23}$

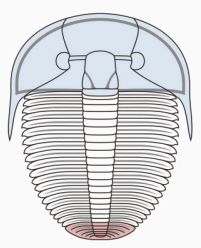

I

$\mathrm{S}_{28}$

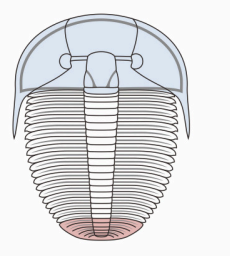

$\mathrm{S}_{4}$

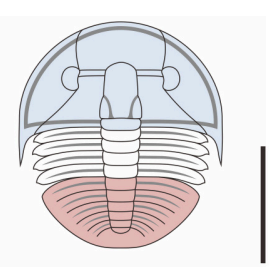

$\mathrm{S}_{9}$

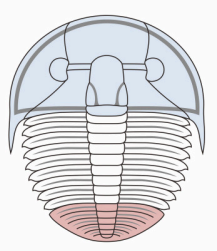

$\mathrm{S}_{14}$

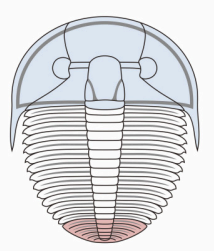

$\mathbf{S}_{19}$

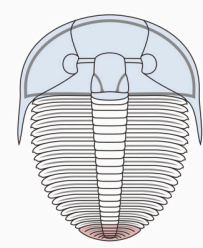

$\mathrm{S}_{24}$

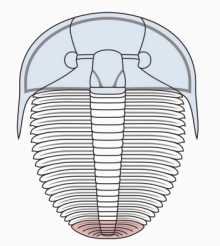

$\mathrm{S}_{29}$

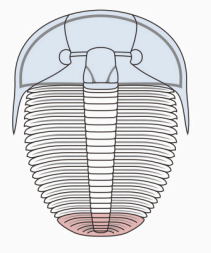

FIGURE 5 | Meraspid (stages $\mathbf{s}_{\mathbf{0}}-\mathbf{s}_{\mathbf{1 9}}$ ) and holaspid (stages $\mathbf{s}_{\mathbf{2 0}}-\mathbf{s}_{\mathbf{3 2}}$ ) ontogeny of $\boldsymbol{A}$. koninckii morphotype $\mathbf{t}_{\mathbf{2 0}}$. All stages are shown at the same size (body length), so as to highlight shape changes with growth. Scale bars $=1 \mathrm{~mm}$. A schematic view of the same ontogeny is shown in Figures $\mathbf{6}, \mathbf{7}$. 
morphological condition or physiological state correlated to size, as it is common for important developmental transitions among extant arthropods (e.g., metamorphosis). The two hypotheses produce different expectations about the size distribution of the individuals with 18-22 thoracic segments, for the differential size of the pygidium in the five morphotypes, and on the probability of witnessing individuals with more than 22 thoracic segments (never observed in more than 10,000 specimens inspected).

All these lines of evidence favor the view that the adult number of thoracic segments was determined relatively early in ontogeny, rather than at the very end of the meraspid period in association with a critical size threshold (Fusco et al., 2004).

\section{AULACOPLEURA KONINCKII GROWTH}

\section{Growth Rates}

In most arthropods the post-embryonic growth of external structures occurs mainly in a stepwise manner, paced by the molt cycle. A constant rate of size increase between molts, the socalled Dyar's rule (Dyar, 1890), is considered the "default mode" for arthropod growth (Minelli and Fusco, 2013), although the same species can exhibit different rates for separate sections of ontogeny (e.g., juvenile vs. adult) and separate morphological characters (ontogenetic allometry, see below). High levels of conformity to Dyar's rule have been reported for different characters and different portions of the ontogeny of various trilobites (Chatterton and Speyer, 1997; Fusco et al., 2012).

In Fusco et al. (2004) and Hong et al. (2014) we detected constant per-stage growth rates in most A. koninckii morphological characters during the meraspid period, with the notable exceptions of those under the influence of a growth gradient (i.e., the axial sections of the cephalon, the length of thoracic segments, the length of the thorax and the length of the pygidium, see below) and those influenced by thoracic segment release (the length of the thorax and the length of the pygidium, see above). Per-stage growth rates were in the range 1.08-1.12, among the lowest values recorded in trilobites (Fusco et al., 2012) and in arthropods in general (Minelli and Fusco, 2013).

Holaspid per-stage growth rates for A. koninckii are not accessible to direct study, because, as in most other trilobites, holaspid specimens cannot be assigned to a stage independently of their size. However, using a compound measure of the cephalon (centroid size based on 15 landmarks; Figure 3) as a proxy for the stage, it is possible to compare meraspid with holaspid growth (see Supplementary Appendix). Trunk length growth rates were larger than cephalic length growth rates throughout ontogeny, which produced a progressive increase in the relative length of the trunk with respect to the cephalon, although differentials were smaller during the holaspid period (Figures 5, 6). As specimens of the different morphotypes entered the holaspid period at a different stage (from $s_{18}$ for $t_{18}$, to $s_{22}$ for $t_{22}$ ) and trunk length growth rate was higher during the meraspid period (1.115) than in the holaspid period (1.103), during the holaspid period morphotypes with more thoracic segments tended to have longer trunks than the morphotypes with less thoracic segments, as a consequence of a prolonged meraspid period (Figure 4).

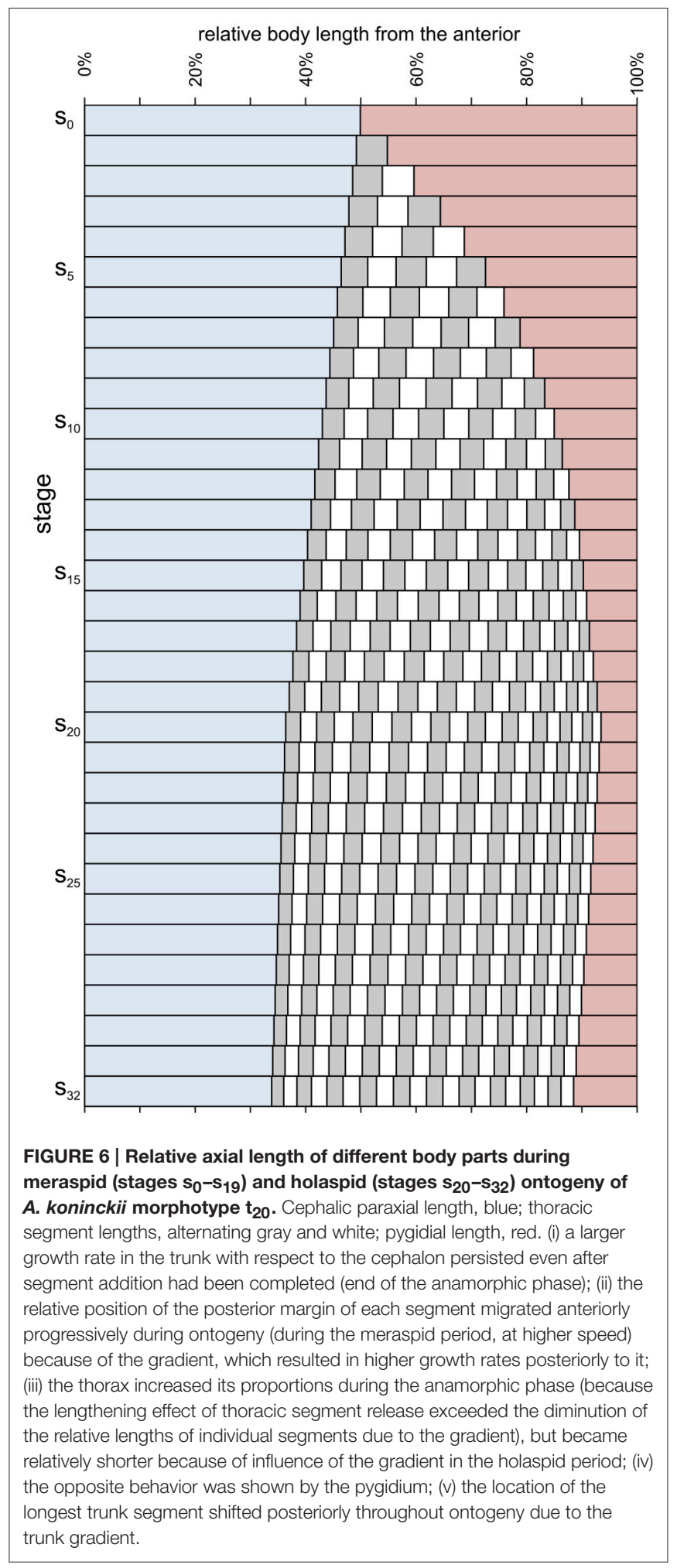

\section{Ontogenetic Allometry}

Compared to many other arthropods, including some other trilobites, there were no prominent shape changes associated with growth during $A$. koninckii ontogeny. Nonetheless, as can be appreciated in Figure 5, main body proportions changed 


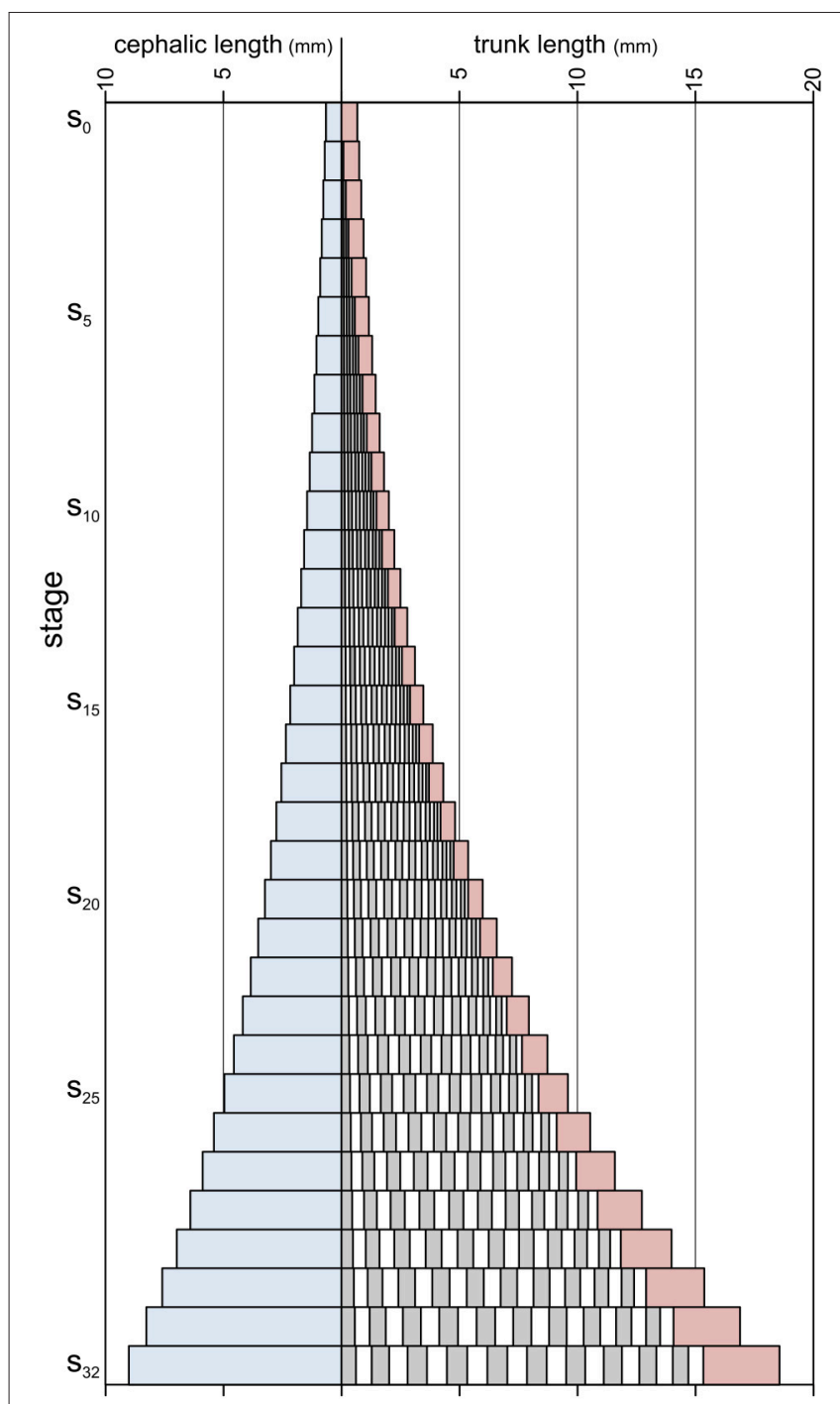

FIGURE 7 | Absolute axial lengths of different body parts during meraspid (stages $s_{0}-s_{19}$ ) and holaspid (stages $s_{20}-s_{32}$ ) ontogeny of $\boldsymbol{A}$. koninckii morphotype $\mathbf{t}_{\mathbf{2 0}}$. Cephalic paraxial length, blue; thoracic segments lengths, alternating gray and white; pygidial length, red.

significantly and steadily throughout both meraspid and holaspid developmental stages.

In Hong et al. (2014) we investigated the ontogenetic allometry of $A$. koninckii through geometric morphometrics (Klingenberg, 2010, 2016), by analyzing 22 landmarks positioned on the cephalon, thorax, and pygidium (Figure 3 ). The addition of new trunk segments during the meraspid period and the persistently higher growth rates of the trunk region meant that the most striking allometry was the expansion of the trunk region compared to the cephalon (Figure 6), consistent with the analysis of axial growth rates (see above). A second major effect was that during the meraspid phase, despite the balance between addition of new segments in the subterminal region of the trunk (one segment per stage) and the release of the anteriormost pygidial segments into the thorax (one segment per stage), the relative size of the pygidium decreased, only to increase again during the subsequent holaspid period (Figure 6). The latter was due to a relatively higher growth rates toward the posterior end of the trunk when segment release had ceased (see below). Other ontogenetic shape changes in the pygidium during the holaspid period include straightening of the arched anterior margin, and axial shortening and narrowing. Within the cephalon, ontogenetic allometry includes expasnsion of the pleural regions of the cephalon relative to the glabella and palpebral lobes, declining relative size of the eyes and the glabella, and narrowing of the intraocular distance. No sharp transition was identified in the cephalic growth pattern associated with the meraspid/holaspid transition.

\section{Growth Compensation}

Arthropod developmental systems are generally able to buffer, at least to some extent, the effects of factors perturbing growth (developmental noise). Buffering can employ different mechanisms, among which is a stage-by-stage feedback mechanism that continuously corrects size increments. This is called compensatory growth (also termed targeted growth or convergent growth). Compensatory growth, at least across a few ontogenetic stages, has been reported for many arthropod taxa, and among insects and crustaceans in particular (Minelli and Fusco, 2013). However, with the exception of a few model systems (all within the Insecta), the underlying developmental machinery that implements it is poorly understood (Nijhout et al., 2010).

In the absence of any growth compensation, a progressive increase in the within-stage size variation is expected along ontogeny. In A. koninckii, we found no evidence of such an increase in variation during meraspid period in any of several morphometric characters investigated, a distinctive feature of compensatory growth (Fusco et al., 2004; Hong et al., 2014). Aulacopelura koninckii provides among the oldest evidence of compensatory growth in Metazoa.

\section{Growth Gradients}

A growth gradient is a distribution of differential growth rates along a body axis. In A. koninckii we detected two axial growth gradients: one in the cephalon, with growth rates declining from anterior to posterior, and one in the trunk, with opposite polarity, with growth rates declining from posterior to anterior (Fusco et al., 2014, 2016). The two gradients were operating during both meraspid and holaspid periods, although the holaspid gradients were flatter than corresponding meraspid gradients.

Using the meraspid trunk data (where size-independent stage assignment is coupled to the many axial landmarks, the boundaries of the thoracic segments) we contrastively tested two alternative hypotheses of growth control associated with the gradient (Fusco et al., 2014): (i) a segment-specific control, with individual segments representing independent morphogenetic fields with autonomous differential growth progressions, and (ii) a regional control, with the trunk representing a single morphogenetic field, with segment growth depending on their relative position along the main axis. Morphometric analyses support the second hypothesis, with segmental growth depending on a form of positional specification along the trunk main axis, governed by a continuous, steady growth gradient. 
Moreover, the specific decaying shape of the gradient suggests it derived from the linear transduction of a graded signal, similar to those commonly provided by morphogens in extant organisms.

Available data do not permit testing of meraspid and holaspid growth gradients in the cephalon and the holaspid growth gradient in the trunk in the same way, but their shapes are compatible with the mechanism of growth control found in the meraspid trunk. Thus, the same type of growth control, based on positional specification, may have operated in the two main body regions and during most of the post-embryonic ontogeny of $A$. koninckii (Fusco et al., 2016).

Morphogen gradients are thought to be a common way in which positional specification is implemented in extant organisms, where they play a fundamental role in pattern formation and growth (Schwank and Basler, 2010). To our knowledge, A. koninckii provides the oldest evidence of positional specification in axial growth control in Bilateria.

The gradients had significant influence on ontogenetic allometry, especially in the trunk, where they were steeper and associated with thoracic segment release. Despite the fact that the gradient did not vary within meraspid or within holaspid ontogeny, during both periods the different portions of the trunk (e.g., the thoracic segments) experienced a slightly decreasing growth rate because their relative position within the trunk changed (shifting toward the anterior) as a consequence of the gradient which caused the more posterior portions to have larger growth rates (Figures 5-7).

Segment release had the effect of shortening the relative length of the pygidium, overcoming the influence of larger growth rates within the pygidium resulting from the gradient (which produced an effective ontogenetic increase in pygidial length only after segment release had ceased). Combining this with the fact that specimens of the different morphotypes terminated thoracic segment release at different stages (from $s_{18}$ for $t_{18}$, to $s_{22}$ for $t_{22}$ ), morphotypes with more thoracic segments tended to have relatively shorter pygidia during holaspid period than the morphotypes with less thoracic segments (Figure 4).

\section{DISCUSSION}

Although papers describing trilobite ontogeny are commonly accompanied by drawings that represent ontogenetic series, the reconstruction presented herein (Figures 4-7) differs in that morphometric character estimates were derived by applying previously inferred growth and segmentation dynamics, as discussed in sections 4 and 5 above. The morphologies of this reconstruction thus come from an understanding of the way in which growth and segmentation were executed in this animal, rather than simply being an attempt to graphically represent mean form at a particular stage. This also allowed us to estimate the morphology of some instars for which measurable specimens are not presently available. When similar studies of the development of other trilobites are completed, this method will provide an effective way to illustrate visually the morphological consequences of systematic differences in developmental dynamics and control. Details of how this reconstruction was made are provided in the Supplementary Appendix.

Aulacopleura koninckii was among the first species for which trilobite growth stages were described, in a work that pioneered the reporting of fossilized ontogenies (Barrande, 1852). By utilizing large numbers of specimens Barrande showed that forms previously recognized by Hawle and Corda (1847) as different trilobite taxa were, in fact, ontogenetic variants of a significantly smaller number of species. The description of ontogenetic changes, where accessible, has since become a standard part of paleontological analysis and increasingly has employed quantitative methods to describe and differentiate modes of development. This is particularly true for those groups, generally skeletonized, for which significant numbers of fossilized specimens are available. Beside other fossilized arthropod taxa, such as Rehbachiella (Walossek, 1993) and Bredocaris admirabalis (Müller and Walossek, 1988), examples include echinoderms (Smith, 2005; Rahman et al., 2015), ammonoid molluscs (Gerber et al., 2007; De Beats et al., 2013), fish (Johanson et al., 2010), dinosaurs (Erickson et al., 2017), and early mammals (ChinsamyTuran and Hurum, 2006). Among trilobites, analyses have included testing whether differences between the ontogenies of close relatives reveal strict heterochronic change or other types of developmental repatterning (e.g., Hunda and Hughes, 2007), and in patterns of ontogenetic and static character covariation (Gerber and Hopkins, 2011; Webster and Zelditch, 2011a,b). Likewise, progress has also been made in the establishment of ontogenetic series for a range of soft-bodied fossils including fascinating, if sometimes controversial, forms from the Cambrian (e.g., Yue and Bengtson, 1999; Harvey et al., 2010; Haug and Haug, 2015) and even earlier (Hoyal Cuthill and Conway Morris, 2014).

Most paleontological ontogenetic studies (including some that are quantitative) remain descriptive in that they characterize and compare developmental patterns, but provide limited information on the mechanisms that controlled them. However, where fossil ontogenies are unusually rich both in terms of the span of developmental stages represented and in the number of individuals available for each stage, as here in A. koninckii, it is possible to frame and test specific hypotheses about how aspects of development were controlled. Among trilobites A. koninckii offers an unusually wide range of insights, as we have seen, but increasingly others are being recognized. For example, evidence of compensatory growth has recently been reported in Olenellus gilberti, a species living approximately 80 million years before $A$. koninckii (Webster, 2015).

A sound assessment of the relevance of the paleo-evo-devo approach to arthropod evolution in general requires that the investigation undertaken into $A$. koninckii is expanded to a variety of other trilobites including those showing different morphotypes and developmental modes, and to other extinct arthropod taxa. This should permit identification of aspects of developmental control conserved among all members of the clade, and those that varied within it. In this regard, a focus on the early Cambrian is likely to bear particular fruit. Firstly, trilobites of this age are phylogenetically basal within the clade and might thus yield insights into the original developmental 
condition of the clade from which derived forms, such as A. koninckii, evolved. Secondly, several relatively complete ontogenies of articulated species are already known from this time, mostly from parts of China (e.g., Dai et al., 2014, 2016; Hou et al., 2015, 2017), offering potential insights into the nature of variation in developmental controls among close relatives.

In summary, looking beyond the taxonomic boundaries of trilobites and arthropods, it seems clear that a paleoevo-devo approach to the study of evolution can convey two main types of insight. Firstly, through a phylogenetic comparative approach, developmental data about extinct taxa can contribute to elucidating both the state of developmental characters at ancient nodes, and the state transitions of the same characters along the branches of an evolutionary tree. Moreover, because the geological age of extinct taxa makes the branches connecting them to the rest of the tree relatively short (in terms of evolutionary time), uncertainties about the exact branching topology affect inferences about primitive character state conditions less strongly (Donoghue et al., 1989; Fusco et al., 2014). Secondly, the possibility of directly investigating the mechanisms controlling developmental processes allows us to explore the evolution of developmental mechanisms, rather than simply the evolution of the developmental patterns that they produce. Both kinds of data and investigation can contribute significantly to the study of the evolvability of developmental

\section{REFERENCES}

Barrande, J. (1852). Systême Silurien du Centre de la Bohême, IÈRE Partie: Recherches Paléontologiques, Vol. I. Texte (Crustacés: Trilobites). Prague; Paris.

Chatterton, B. D. E., and Speyer, S. E. (1997). "Ontogeny," in Arthropoda 1, Trilobita. Part O (Revised) Treatise on Invertebrate Paleontology, ed H. B. Whittington (Boulder, CO; Lawrence, KS: Geological Society of America; University of Kansas), 173-247.

Chinsamy-Turan, A., and Hurum, J. H. (2006). Bone structure and growth patterns of early mammals. Acta Palaeontol. Pol. 51, 325-338. doi: 10.7717/peerj.325

Cock, A. G. (1966). Genetical aspects of metrical growth and form in animals. Q. Rev. Biol. 41, 131-190. doi: 10.1086/404940

Dai, T., Zhang, X.-L., and Peng, S.-C. (2014). Morphology and ontogeny of Hunanocephalus ovalis (trilobite) from the Cambrian of South China. Gondwana Res. 25, 991-998. doi: 10.1016/j.gr.2013.05.004

Dai, T., Zhang, X.-L., and Peng, S.-C. (2016). Morphology and development of the eodiscoid trilobite Tsunyidiscus yanjiazhaiensis from the Cambrian (Stage 3, Series 2) of South China. J. Syst. Palaeontol. 14, 75-89. doi: 10.1080/14772019. 2015.1005699

De Beats, K., Clug, C., and Monnet, C. (2013). Intraspecific variability through ontogeny in early ammonoids. Paleobiology 39, 75-94. doi: 10.1666/00948373-39.1.75

Donoghue, M. J., Doyle, J. A., Gauthier, J., Kluge, A. G., and Rowe, T. (1989). The importance of fossils in phylogeny reconstruction. Ann. Rev. Ecol. Syst. 20, 431-460. doi: 10.1146/annurev.es.20.110189.002243

Dyar, H. G. (1890). The number of molts of lepidopterous larvae. Psyche 5, 420-422. doi: 10.1155/1890/23871

Erickson, G. M., Zelenitsky, D. K., Kay, D. I., and Norell, M. A. (2017). Dinosaur incubation periods directly determined from growth-line counts in embryonic teeth show reptilian-grade development. Proc. Nat. Acad. Sci. U.S.A. 114, 540-545. doi: 10.1073/pnas.1613716114

Fusco, G. (2001). How many processes are responsible for phenotypic evolution? Evol. Dev. 3, 279-286. doi: 10.1046/j.1525-142x.2001.003004279.x

Fusco, G. (2015). For a new dialogue between theoretical and empirical studies in evo-devo. Front. Ecol. Evol. 3:97. doi: 10.3389/fevo.2015.00097 patterns and processes in the total (stem + crown) group of interest.

\section{AUTHOR CONTRIBUTIONS}

$\mathrm{NH}$ conducted initial investigations and data collection for A. koninckii, later aided by $\mathrm{PH}$ who produced the current landmark dataset. Analyses were conceived and performed by GF, $\mathrm{PH}$, and NH. GF conceived of the full reconstruction presented herein and JH drew the reconstructions in Figures 4, 5.

\section{FUNDING}

This work was funded by NSF EAR-0616574 to NH and Basic Research Project (GP17-3111-1) of KIGAM to PH.

\section{ACKNOWLEDGMENTS}

We thank the reviewers and editors of this work for their careful suggestions that improved the paper.

\section{SUPPLEMENTARY MATERIAL}

The Supplementary Material for this article can be found online at: http://journal.frontiersin.org/article/10.3389/fevo. 2017.00037/full\#supplementary-material

Fusco, G., Garland, T. Jr., Hunt, G., and Hughes, N. C. (2012). Developmental trait evolution in trilobites. Evolution 66, 314-329. doi: 10.1111/j.1558-5646.2011.01447.x

Fusco, G., Hong, P. S., and Hughes, N. C. (2014). Positional specification in the segmental growth pattern of an early arthropod. Proc. R. Soc. B 281:20133037. doi: $10.1098 /$ rspb.2013.3037

Fusco, G., Hong, P. S., and Hughes, N. C. (2016). Axial growth gradients across the post-protaspid ontogeny of the Silurian trilobite Aulacopleura koninckii. Paleobiology 42, 426-438. doi: 10.1017/pab.2016.5

Fusco, G., Hughes, N. C., Webster, M., and Minelli, A. (2004). Exploring developmental modes in a fossil arthropod: growth and trunk segmentation of the trilobite Aulacopleura konincki. Am. Nat. 163, 167-183. doi: 10.1086/ 381042

Fusco, G., and Minelli, A. (2013). "Arthropod segmentation and tagmosis," in Arthropod Biology and Evolution. Molecules, Development, Morphology, eds A. Minelli, G. Boxshall, and G. Fusco (Berlin; Heidelberg: Springer-Verlag), 197-221.

Gerber, S., and Hopkins, M. J. (2011). Mosaic heterochrony and evolutionary modularity: the trilobite genus Zacanthopsis as a case study. Evolution 65, 3241-3252. doi: 10.1111/j.1558-5646.2011.01363.x

Gerber, S., Neige, P., and Eble, G. J. (2007). Combining ontogenetic and evolutionary scales of morphological disparity: a study of early Jurassic ammonites. Evol. Dev. 9, 472-482. doi: 10.1111/j.1525-142X.2007.00185.x

Harvey, T. H., Dong, X. P., and Donoghue, P. C. (2010). Are paleaoscolecids ancestral ecdysozoans? Evol. Dev. 12, 177-200. doi: 10.1111/j.1525-142X.2010. 00403.x

Haug, J. T., and Haug, C. (2015). Worm palaeo-evo-devo-the ontogeny of Ottoia prolifica from the Burgess Shale. Res. Rev. J. Zool. Sci. 3, 3-14. Available online at: https://www.rroij.com/ArchiveJZS/zoological-sciences-archive.php? month $=$ November\&\&year $=2015$ \&journal $=$ jzs

Haug, J. T., Müller, C. H. G., and Sombke, A. (2013). A centipede nymph in Baltic amber and a new approach to document amber fossils. Org. Divers. Evol. 1, 425-432. doi: 10.1007/s13127-013-0129-3

Hawle, I., and Corda, A. J. C. (1847). Prodrom einer Monographie der böhmischen Trilobiten. Abh. Königlich. böhm. Ges. der Wiss. 5, 1-176. 
Hong, P. S., Hughes, N. C., and Sheets, H. D. (2014). Size, shape, and systematics of the Silurian trilobite Aulacopleura koninckii. J. Paleontol. 88, 1120-1138. doi: $10.1666 / 13-142$

Hou, J.-B., Hughes, N. C., Lan, T., Yang, J., and Zhang, X.-G. (2015). Early postembryonic to mature ontogeny of the cheiruroideid trilobite Duodingia duodingensis from the lower Cambrian (Series 2) of southern China. Pap. Palaeontol. 1, 497-513. doi: 10.1002/spp2.1021

Hou, J.-B., Hughes, N. C., Yang, J., Lan, T., Zhang, X.-G., and Dominguez, C. (2017). Ontogeny of the articulated yiliangellinine trilobite Zhangshania typica from the lower Cambrian (Series 2, Stage 3) of southern China. J. Paleontol. 91, 86-99. doi: 10.1017/jpa.2016.118

Hoyal Cuthill, J. F., and Conway Morris, S. (2014). Fractal branching organizations of Ediacaran rangeomorph fronds reveal a lost Proterozoic body plan. Proc. Nat. Acad. Sci. U.S.A. 111, 13122-13126. doi: 10.1073/pnas.1408542111

Hughes, N. C. (2003). Trilobite body patterning and the evolution of arthropod tagmosis. Bioessays 25, 386-395. doi: 10.1002/bies.10270

Hughes, N. C., and Chapman, R. E. (1995). Growth and variation in the Silurian proetide trilobite Aulacopleura konincki and its implications for trilobite palaeobiology. Lethaia 28, 333-353. doi: 10.1111/j.1502-3931.1995. tb01824.x

Hughes, N. C., Chapman, R. E., and Adrain, J. M. (1999). The stability of thoracic segmentation in trilobites: a case study in developmental and ecological constraints. Evol. Dev. 1, 24-35. doi: 10.1046/j.1525-142x.1999.99005.x

Hughes, N. C., Kř́ǐž, J., Macquaker, J. H. S., and Huff, W. D. (2014). The depositional environment and taphonomy of the Homerian Aulacopleura shales fossil assemblage near Loděnice, Czech Republic (Prague Basin, Perunican microcontinent). Bull. Geosci. 89, 219-238. doi: 10.3140/bull.geosci.1414

Hughes, N. C., Minelli, A., and Fusco, G. (2006). The ontogeny of trilobite segmentation: a comparative approach. Paleobiology 32, 602-627. doi: $10.1666 / 06017.1$

Hunda, B. R., and Hughes, N. C. (2007). Evaluating paedomorphic heterochrony in trilobites: the case of the diminutive trilobite Flexicalymene retrorsa minuens from the Cincinnatian Series (Upper Ordovician), Cincinnati region. Evol. Dev. 9, 483-498. doi: 10.1111/j.1525-142X.2007.00186.x

Johanson, Z., Kearsley, A., den Blaauwen, J., Newman, M., and Smith, M. M. (2010). No bones about it: an enigmatic Devonian fossil reveals a new skeletal framework a potential role of loss of gene regulation. Semin. Cell Dev. Biol. 21, 414-423. doi: 10.1016/j.semcdb.2009.10.011

Kliman, R., M. (ed.). (2016). Encyclopedia of Evolutionary Biology. Oxford: Academic Press.

Klingenberg, C. P. (2010). Evolution and development of shape: integrating quantitative approaches. Nat. Rev. Genet. 11, 623-635. doi: 10.1038/nrg2829

Klingenberg, C. P. (2016). Size, shape, and form: concepts of allometry in geometric morphometrics. Dev. Gen. Evol. 226, 113-137. doi: 10.1007/s00427-016-0539-2

Minelli, A., and Fusco, G. (eds.) (2008). Evolving Pathways-Key Themes in Evolutionary Developmental Biology. Cambridge: Cambridge University Press.

Minelli, A., and Fusco, G. (2013). “Arthropod post-embryonic development," in Arthropod Biology and Evolution. Molecules, Development, Morphology, eds A. Minelli, G. Boxshall, and G. Fusco (Berlin; Heidelberg: Springer-Verlag), 91-122.

Minelli, A., Fusco, G., and Hughes, N. C. (2003). Tagmata and segment specification in trilobites. Spec. Pap. Palaeontol. 70, 31-43.

Moczek, A. P. (2015). Re-evaluating the environment in developmental evolution. Front. Ecol. Evol. 3:7. doi: 10.3389/fevo.2015.00007

Müller, G. B. (2007). Evo-devo: extending the evolutionary synthesis. Nat. Rev. Genet. 8, 943-949. doi: 10.1038/nrg2219
Müller, K. J., and Walossek, D. (1988). External morphology and larval development of the Upper Cambrian maxillopod Bredocaris admirabilis. Fossils Strata, 23, 1-70.

Nijhout, H. F., Roff, D. A., and Davidowitz, G. (2010). Conflicting processes in the evolution of body size and development time. Phil. Trans. R. Soc. B 365, 567-575. doi: 10.1098/rstb.2009.0249

Rahman, I. A., Waters, J. A., Sumrall, C. D., and Astolfo, A. (2015). Early post-metamorphic, Carboniferous blastoid reveals the evolution and development of the digestive system in echinoderms, Biol. Lett. 11:20150776. doi: $10.1098 / \mathrm{rsbl} .2015 .0776$

Sánchez, M. (2012). Embryos in Deep Time, The Rock Record of Biological Development. Los Angeles, CA: University of California Press.

Schwank, G., and Basler, K. (2010). Regulation of organ growth by morphogen gradients. Cold Spring Harb. Perspect. Biol. 2:a001669. doi: 10.1101/cshperspect. a001669

Smith, A. B. (2005). "Growth and form in echinoids: the evolutionary interplay of plate accretion and plate addition," in Evolving Form and Function: Fossils and Development, ed D. E. G. Briggs (New Haven, CT: Peabody Museum of Natural History), 181-195.

Walossek, D. (1993). The Upper Cambrian Rehbachiella and the phylogeny of Branchiopoda and Crustacea. Fossils Strata 32, 1-202. doi: 10.1111/j.1502-3931.1993.tb01537.x

Webster, M. (2015). Ontogeny and intraspecific variation of the early Cambrian trilobite Olenellus gilberti, with implications for olenelline phylogeny and evolutionary trends in phenotypic variation. J. Syst. Palaeontol. 13, 1-74. doi: 10.1080/14772019.2013.852903

Webster, M., and Zelditch, M. L. (2011a). Modularity of a Cambrian ptychoparioid trilobite cranidium. Evol. Dev. 13, 96-109. doi: 10.1111/j.1525-142X.2010. 00459.x

Webster, M., and Zelditch, M. L. (2011b). Evolutionary lability of integration in Cambrian ptychoparioid trilobites. Evol. Biol. 38, 144-162. doi: $10.1007 / \mathrm{s} 11692-011-9110-2$

Wilson, L. A. B. (2013). The contribution of developmental palaeontology to extensions of evolutionary theory. Acta Zool. 94, 254-260. doi: 10.1111/j.1463-6395.2011.00539.x

Yuan, W.-W., Li, L.-Z., Zhou, Z.-Y., and Zhang, C.-S. (2001). Ontogeny of the Silurian trilobite Aulacopleura (Aulacopleura) wulongensis Wang of western Hubei and its implications for the phylogeny of the Aulacopleurinae. Acta Palaeontol. Sin. 40, 388-398.

Yue, Z., and Bengtson, S. (1999). Embryonic and post-embryonic development of the Early Cambrian cnidarian Olivooides. Lethaia 32, 181-195.

Conflict of Interest Statement: The authors declare that the research was conducted in the absence of any commercial or financial relationships that could be construed as a potential conflict of interest.

The reviewer NS and handling Editor declared their shared affiliation, and the handling Editor states that the process nevertheless met the standards of a fair and objective review.

Copyright (c) 2017 Hughes, Hong, Hou and Fusco. This is an open-access article distributed under the terms of the Creative Commons Attribution License (CC BY). The use, distribution or reproduction in other forums is permitted, provided the original author(s) or licensor are credited and that the original publication in this journal is cited, in accordance with accepted academic practice. No use, distribution or reproduction is permitted which does not comply with these terms. 